\title{
Presupposition Trigger in the Articles of Toastmasters Magazine
}

\author{
Rizki Hardiyanti \\ English Applied Linguistics Study Program Postgraduate \\ Universitas Negeri Medan, UNIMED \\ Medan, Sumatera Utara 20371, Indonesia \\ rizkihardiyanti0@gmail.com \\ Busmin Gurning \\ English Applied Linguistics Study Program Postgraduate \\ Universitas Negeri Medan, UNIMED
}

\author{
Medan, Sumatera Utara 20371, Indonesia \\ busmingurning@yahoo.com
}

\author{
Anni Holila Pulungan \\ English Applied Linguistics Study Program Postgraduate \\ Universitas Negeri Medan, UNIMED \\ Medan, Sumatera Utara 20371, Indonesia \\ anniholilapulungan@gmail.com
}

\begin{abstract}
Presupposition has been studied by many linguists. Presupposition is the speaker's/ writer's assumption before saying something. The paper aims to analyze the way of presupposition triggers of an author's writing through triggers that asserts implicit or explicit meaning in sentences, clauses, phrases and words in the articles of Toastmasters magazine. Accordingly, 18 articles Toastmasters Magazine 2016 start from July until December are analyzed in terms of presupposition triggers namely: definite description, implicative verb, factive verb, change of state verbs, verbs of judging, counter factual verbs, conventional item, iteratives item, cleft construction, questions, adverbial clause, comparative sentence, counterfactual conditional clause, non-restrictive relative clause and other presupposition triggers are: additive particles, discourse particles, manner adverbs, quantifiers and discourse connectives. The result of the study indicated that the factive verb is the most frequent trigger occurred in articles while verb of judging is the least one.
\end{abstract}

Keywords-Articles; Presupposition; Presupposition Triggers

\section{INTRODUCTION}

Presupposition as the way to know the writer's assumption and intended meaning on writing certain news event in the articles. The writer has the background belief and assumption to write something on the articles on the purpose of influencing the readers about the information, which the author has given.

A presupposition is something the speaker assumes to be the case prior to making an utterance [1]. This means the speaker's or writer's assumption is already believed in truth by the addressee. Presupposition as "the common ground" embedded in an utterance which is taken for granted by all the participants i.e. speaker \& listener, or writer \& reader [2]. It means that speakers/ writers assume background information and already known to be true by their listeners/ readers.

Moreover, presuppositions in general are an inherent property of human language use. Indeed it is virtually impossible to utter or write a single sentence of any consequence without making some kind of assumption and hence without the use of presupposition [3]. Presupposition as a property of language use is generally exploited by language users [4]. So, presupposition is one of language use phenomena, and it is taken for granted since it is belief and background knowledge of someone.

In addition, presupposition is the implicit information of proposition embedded in a sentence or utterance. Particularly in linguistics, semantics and pragmatics attach mutual importance to its research. Presupposition has been defined various. Thus, presupposition is about the speakers' or writers' assumption of certain information already known by their listener or reader. There is the implicit meaning conveyed by the speaker or writer through the use of particular words, phrases and clauses.

This study focuses on pragmatic presupposition. Pragmatic presuppositions are necessary in order to understand what people doing with their language in order to reach that understanding, we need to use our skills both of conversationally implying and of pragmatically presupposing even with the best of wills and the cleverest techniques, it sometimes is impossible to ferret out all the pragmatic presuppositions and construct all the necessary implicatures in order to make sense of what is being said or written [5].

Moreover, presupposition can be form not only in positive statement, but also it cannot be change in negation. Presupposition can be treated as a relationship of two propositions, $\mathrm{p}$ and $\mathrm{q}$ [1]. It represents in example below.

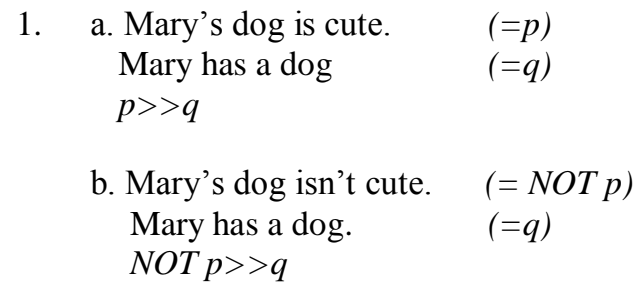


The examples above show that presupposition described as constancy under negation, which can survive in negation and thus they presuppose same truth-conditional. In addition, presupposed sentences can be seen in semantic and pragmatic. These two branches of linguistics bring out the understanding of the concept of presupposition differently.

Moreover, presupposition is pieces of information, which are associated with certain lexical items or syntactic constructions [6]. This certain lexical items or syntactic construction is called by triggers. The triggers aim to distinguish what is presupposed to be taken granted by the speakers or writers. So, it can be concluded that presupposition triggers are the item that is expressed by some particular words or construction which sign the presence of presupposed meaning in text or utterance. [2] There are linguistic constructions at speakers or writers' disposal to communicate intended information without stating them [7]. This survival makes triggers in presupposition determine in part of words, phrases and clauses.

Furthermore, presupposition can be used to analyze the text of article's magazine. In processing presupposition, the intended meaning is assumed to be true based on the speaker's utterance or the writer's statement and it is analyzed by the hearer or the reader. In consequence, presupposition can be used by the readers to know the intended meaning of the articles in magazine. The role of presupposition in mass media's use of language is of paramount importance in that media writers attempt consciously or unconsciously to influence the audience understanding of news events [7]. In addition, presupposition has been associated with the use of words phrases and structures as indicators of potential presupposition which can only become actual presuppositions in contexts with speakers/ writers [1]. So, the reader will not only read the text but also understand the truth-value and the context meaning of the text implied and takes the existent of referent on trust meaning by these triggers.

Article is a piece of writing targeted for a specific interest group. The article attracts the reader's attention through the story, opinion, tips, report and description. Especially in the articles of Toastmasters magazine, the story and opinion about public speaking, leadership skill are descriptive, persuasive and argumentative, that is, their main objective is to influence the readers to accept the articles' intended interpretation of news events. The readers usually tend to not examine the truth-value of the information and they take for granted when reading the article. Thus, this paper intends to examine the implied meaning of presupposition triggers in the articles of Toastmasters magazine.

Presupposition is also found in legislative text with findings that presupposition could be a useful stylistic means to keep legislative text free from unnecessary clutter that merely elaborates on the obvious. Some triggers such as definite descriptions and adverbials have been examined to express expansive function [8]. This study discusses about presupposition in the articles of Toastmasters magazine. The study, particular, aims at identifying the realization of the presupposition triggers in the articles of Toastmasters magazine.
In this study, the triggers are classified into three major types: existential (definite descriptions); lexical (implicative and factive verbs, change of state verbs and verbs of judging, counter factual verbs, conventional items and iteratives); and structural (cleft constructions, Wh-questions, adverbial and comparative constructions, and counter factual conditionals, and non-restrictive clauses) [1] [2]. Furthermore, the elements that introduce presuppositions are called presupposition triggers. The triggers show that the certain linguistic expression can trigger the presupposed meaning. Thus, it can be concluded that presupposition triggers are some certain linguistic expression or item, which can be formed in existential, lexical and structural construction, which aims to carry presupposed meaning in text. These triggers is used to seek the realization of presupposition triggers in such sentence or passage which contains presupposed meaning in text.

\section{MethOD}

This study is qualitative design. Qualitative research is characterized by its aims, which related to understanding some aspect of social life, and its methods which (in general) generate words, rather than numbers, as data for analysis. [9] The data analysis technique is the interactive model. Purpose an analysis as three concurrent flowed of activity are data condensation, data display, and conclusion drawing / verification [10].

The data of this study are phrases and clauses of presupposition triggers in articles of Toastmasters magazine. The sources of this study are articles of 6 Toastmasters Magazine 2016 start from July until December. How data collect will begin by picking out three articles of each edition Toastmasters magazine. This can be done by searching in the magazines itself or taking the articles in its official website of Toastmasters magazine. After that, articles are selected as the need for this study. Then, finally, sentences in articles are listed where clauses ore phrases will be examined further whether they trigger presupposition or not based on classification by Levinson (1983) and Yule (1996). The frequency and percent of the occurrences of the presupposition triggers are tabulated.

\section{RESUlTS AND DISCUSSION}

\section{A) Results}

Based on the data obtained from eighteen articles of the Toastmasters Magazine, there are 727 sentences selected from eighteen articles. These sentences are analyzed and, then finally, resulted 1890 occurrences which detected using presupposition triggers proposed by Levinson (1983) and Yule (1996) namely definite description, factive verb, implicative verb, change of state verbs, verbs of judging, iterative item, cleft construction, questions, temporal clause, comparative sentence, counterfactual conditional sentence and nonrestrictive relative clause. In addition, there are five others presupposition triggers are detected. They are additive particles, discourse particles, manner adverbs, quantifiers, and discourse connectives. Note that TM stands for Toastmasters Magazine and the mark ' $>>$ ' sign the presupposed meaning of the italic lexical, phrasal or structural form. The following data 
represents the presupposition triggers in the articles of Toastmasters magazine.

\section{1) Definite Description (DD)}

- Mohammed Murad, DTM, Toastmasters' 2014-2015 International President, says giving to the Smedley Fund, as he did recently, can bring you great fulfillment. (TM: Dec '16)

> There exists a man called Mohammed Murad who is the International President of Toastmasters 2014-2015.

The noun phrase Mohammed Murad occurred as presupposed that there exists a man called Mohammed Murad who is the International President of Toastmasters. This meant the existence of that person was available and was newly installed become an International President of Toastmasters.

\section{2) Implicative Verb (IV)}

- I (Angelica Godinho) also make sure all the volunteers are committed, and I distribute tasks and ensure we are keeping Toastmasters' high standards. (TM: July, 2016)

$>$ We (all the volunteers) tried to make Toastmasters' high standards.

The example above showed the use of verb keep in ... we are keeping Toastmasters' high standards presuppose that we (all the volunteers) tried to make Toastmasters' high standards to lead the TLI event in Brazil on January.

\section{3) Factive Verb (FV)}

- Like a true Toastmasters alum, Regan has vowed to bring a more courteous and respectful environment to the proceedings. (The Toastmasters Magazine: August, 2016)

>> Regan brought a more courteous and respectful environment to the proceedings.

The existences of verb vow in example above showed the presence of factive verbs presupposed that Regan brought a more courteous and respectful environment to the proceedings being elected Speaker by his House colleagues like a true Toastmasters alum.

\section{4) Change of State Verb (CSV)}

- "During one spell of World Championships, it seemed that contestants often put on extremely energetic 'performances,' racing back and forth on the stage, using extreme vocal variety or overdoing body language," says Abayasekara, who has judged speech contests at every level of competition. (TM: Nov'16)

> Contestants used not to leave on extremely energetic performances, racing back and forth on the stage, using extreme vocal variety or overdoing body language before World Championships.
The example above inscribed the verb put which presupposed that the contestants did not do extremely energetic performances, racing back and forth on the stage, using extreme vocal variety or overdoing body language before World Championships. But during World Championships the contestants were doing it.

5) Verbs of Judging (VJ)

- His parents didn't show any faith either-Frantz says his father disdained classical music for being "elitist" and his mother accused him of wasting his brain. (TM: Oct '16)

$>$ His mother (Frantz's mother) thought of him wasting his brain.

The example above showed the occurrence of verb accuse, which presupposed that his mother (Frantz's mother) thought of him wasting his brain because of playing classical music in years.

\section{6) Counter Factual Verbs (CFV)}

- Evaluators deliver feedback pretending to have already heard the speeches. It keeps people on their toes. (TM: Dec '16)

$<<$ Evaluators don't hear the speech.

The example above presupposed that evaluators don't hear the speech. In expressing the same meaning of this article that at the very first time the evaluators don't hear the speeches when they deliver feedback but they pretend to do so. Because, there is a fun activity, which called "backward" meeting in which members go through the normal agenda but in reverse order.

\section{7) Conventional Items (CI)}

- His wife, Kelly, is a cabinet member in the Nova Scotia government. (TM: Aug '16)

> Regan is married to Kelly

Based on the example above, the occurrence of noun wife triggered presupposition. The sentence above presupposed Regan is married to Kelly who is a cabinet member in the Nova Scotia government.

\section{8) Iteratives Item (II)}

- His (Belle's) success in rebuilding the club helped him develop a reputation for facilitating, mentoring and promotions, which led to his first professional facilitation opportunity. (TM: Aug '16)

> He (Belle) built the club before.

The example above presented the use of prefix re- in rebuild. The occurrences showed the author was sure that the incidents happened before, even it was still in progress until now or it had already been done. The use of rebuild meant to realize that $\mathrm{He}$ (Wang) built the dying corporate club before. 
9) Cleft Construction (CC)

- "At the end of the day, what really matters is being kind to people," she says. (TM: Sept '16)

> At the end of the day, something (being kind to people) is really matters. You acknowledge that your team members have lives and challenges outside of Toastmasters.

Based on the example above, the occurrence what following infinitive clauses triggered presupposition. The sentence above presupposed at the end of the day, something (being kind to people) is really matters.

10) Questions (QC)

When did you (Heather Turner) make your career move? (TM: Sept '16)

>> You (Heather Turner) made your career move.

The example above obtained the meaning that you (Heather Turner) made her career moved when she decided to do web design for restaurants.

11) Adverbial Clause (AC)

- After making 40 games that failed, he (Reichelt) chalked it up to experience and took a year to regroup. (TM: Dec '16)

>> Reichelt made 40 games.

The example above displayed the use of adverbial clause as the complement of the sentence. The clauses existed after conjunction determined the extra information given by the author. The example above presupposes that Reichelt made 40 games, the games were failed but he didn't quit.

\section{2) Comparative Sentence (CS)}

- So I (Reichelt) made it as simple as possible, narrowing my thinking to colors and shapes. Pac-Man was a big inspiration because I saw how much of a success it has been for over 30 years, and it is really about colors and simple shapes. (TM: Dec '16)

>> Reichelt made the simple game.

Example above appeared the use of positive degree form in I (Reichelt) made it (the game) as simple as possible. This game was inspired by Pac-Man game.

\section{3) Counterfactual Conditional Clause (CCC)}

- "If you had asked me (Regan), when I was 19, 20, 21, if I thought it was likely I'd ever be elected to the House of Commons, let alone as its Speaker, I would have had grave doubts. (TM: Aug '16)

$>$ Y You didn't ask me (Regan) when I was 19, 20, 21. I didn't think it was likely I'd ever elected to the House of Commons, let alone as its speaker and I didn't have grave doubts.
The example above showed the contrary fact which related to presuppose something in meaning you didn't ask me (Regan) when I was 19, 20, 21 and I (Regan) didn't think it was likely I'd ever be elected to the House of Commons, let alone as its Speaker, so I (Regan) didn't have grave doubts. He used it in order to imply the fact of that news and made the opposing claim to be argued.

\section{4) Non- Restrictive Clause (NRC)}

- New activities help keep members engaged, which can lead to better attendance, stronger evaluations and more durable relationships. (TM: Dec '16)

> New activities can lead to better attendance, stronger evaluations and more durable relationships.

Example above presupposed that new activities can lead to better attendance, stronger evaluations and more durable relationships.

\section{5) Additive Particles}

- This choice allows you to make a pre-tax contribution to the Smedley Fund, while also avoiding possible penalties if you do not take your IRA Required Minimum Distribution by year-end. (TM: Dec '16)

>> This choice allows you to make a pre-tax contribution.

Example above presupposed that this choice allows you to make a pre-tax contribution. In expressing the same meaning this article could become this choice allows you to avoid possible penalties if you do not take your IRA Required Minimum Distribution by year-end.

\section{6) Discourse Particles}

- The only way to learn is to acknowledge that you might not have all the answers." (TM: Aug '16)

> There is no other way to learn except to acknowledge that you might not have all the answers.

The example above obtained the meaning that there is no other way to learn except to acknowledge that you might not have all the answers.

\section{7) Manner Adverbs}

- If you get people working for the common good, you can work smoothly together and make progress. (TM: Sept '16)

>> You can work together and make progress.

Example above presupposed that you can work together and make progress. The assertion of that adverb implied the way of working together was smooth. 


\section{8) Quantifiers}

- It took him (Reichelt) another week to finish all of the other levels. (TM: Dec '16)

>> There are the other levels.

The italic clause marked the use of quantifiers. Example above presented the use of all to give other information of event or the fact happened on the event trusted by the author in order to fulfill the fact toward the opinion he referred to presupposed that there are the other levels.

\section{9) Discourse Connectives}

- Over the years I (Heather) developed a really bad temper, primarily I think, because I worked with a lot of chefs who worked that way-yelling, screaming, throwing things. (TM: Sept '16)

> I (Heather) worked with a lot of bad temper chefs as a reason of developing a really bad temper.

The example above presupposes that I (Heather) worked with a lot of bad temper chefs as a reason of developing a really bad temper.

The occurrences of presupposition triggers are mostly found is factive verb and the least one is verbs of judging during the data analysis in articles of the Toastmasters magazine. Factive verb had surpassed as the first mostly dominant presupposition trigger with 513 occurrences or $27.14 \%$, or one fourth more of the whole occurrences of presupposition triggers found in articles. Other triggers followed adverbial clause with 297 occurrences or $15.71 \%$, cleft construction with 196 occurrences or $10.37 \%$, definite description with 186 occurrences or $9.84 \%$, change of state verb with 169 occurrences or $8.94 \%$, comparative sentence with 110 occurrences or $5.82 \%$, implicative verb with 94 occurrences or $4.97 \%$, non- restrictive clause with 68 occurrences or $3.6 \%$, questions with 52 occurrences or $2.75 \%$, iteratives item with 37 occurrences or $1.96 \%$, Counterfactual Conditional Clause with 34 occurrences or $1.8 \%$, counter factual verbs with 4 occurrences or $0.21 \%$, conventional items with 3 occurrences or $0.16 \%$, and verbs of judging with 1 occurrence or $0.05 \%$.

Other triggers, which are considered to presuppose the truth and to provide the information of the authors are found in articles. The additive particles appeared to be the most dominant among other with 34 occurrences or $1.8 \%$ from the whole data analyzed in articles from July until December 2016. It was followed quantifiers with 27 occurrences or $1.43 \%$, the manner adverbs with 24 occurrences or $1.27 \%$, the discourse particles with 23 occurrences or $1.22 \%$ and, the least, discourse connectives with 18 occurrences or $0.95 \%$.
Table I. The occurrences of the presupposition triggers in articles of the Toastmasters magazine

\begin{tabular}{|c|c|c|c|}
\hline No. & Presupposition Triggers & $\begin{array}{l}\text { The Number of } \\
\text { Occurrences in } \\
\text { Articles from July- } \\
\text { December } 2016\end{array}$ & Percentage \\
\hline & $\begin{array}{l}\text { Presupposition triggers } \\
\text { proposed by Levinson } \\
\text { (1983) and Yule (1996) }\end{array}$ & & \\
\hline 1. & Definite Description & 186 & 9.84 \\
\hline 2. & Implicative Verb & 94 & 4.97 \\
\hline 3. & Factive Verb & 513 & 27.14 \\
\hline 4. & Change of State Verb & 169 & 8.94 \\
\hline 5. & Verbs of Judging & 1 & 0.05 \\
\hline 6. & Counter Factual Verbs & 4 & 0.21 \\
\hline 7. & Conventional Items & 3 & 0.16 \\
\hline 8. & Iteratives Item & 37 & 1.96 \\
\hline 9. & Cleft Construction & 196 & 10.37 \\
\hline 10. & Questions & 52 & 2.75 \\
\hline 11. & Adverbial Clause & 297 & 15.71 \\
\hline 12. & Comparative Sentence & 110 & 5.82 \\
\hline 13. & $\begin{array}{c}\text { Counterfactual Conditional } \\
\text { Clause }\end{array}$ & 34 & 1.8 \\
\hline \multirow[t]{2}{*}{14.} & Non- Restrictive Clause & 68 & 3.6 \\
\hline & $\begin{array}{c}\text { Other presupposition } \\
\text { triggers }\end{array}$ & & \\
\hline 15. & Additive Particles & 34 & 1.8 \\
\hline 16. & Discourse Particles & 23 & 1.22 \\
\hline 17. & Manner Adverbs & 24 & 1.27 \\
\hline 18. & Quantifiers & 27 & 1.43 \\
\hline \multirow[t]{2}{*}{19.} & Discourse Connectives & 18 & 0.95 \\
\hline & Total & 1890 & 100 \\
\hline
\end{tabular}

\section{B) Discussion}

Analysis of the chosen articles from Toastmasters magazine reveals that the words, phrases and clauses of the articles put into service presupposition triggers. Comparing to other research, moreover, the result of the occurrence of presupposition triggers in articles of Toastmasters magazine seems to be similar and contrast to the previous researches, which had conducted before. The existential or presupposition through nominalization is the most dominant used presupposition triggers [6].

However, There is also different result that definite description (existential) is the most frequently employed presupposition triggers [5]. Meanwhile, the result of this present study, found that factive verb as a dominant result. Overall, these relevant studies explained that presupposition nearly similar but some are different on the source data, the theory being used and the results.

\section{CONCLUSION}

The presupposition in articles found fourteen triggers during the data analysis in articles. They are Definite description, Implicative Verb, Factive Verb, Change of State Verb, Verbs of Judging, Counter Factual Verbs, Conventional Items, Iteratives Item, Cleft Construction, Questions, Adverbial Clause, Comparative Sentence, Counterfactual Conditional Clause and Non- Restrictive Clause are definitely found during the data analysis. In addition, other triggers which are considered to trigger presupposition in articles, 
namely Additive Particles, Discourse Particles, Manner Adverbs, Quantifiers and Discourse Connectives. The factive verb is found the most frequent trigger occurs in articles while verb of judging is the least one.

\section{REFERENCES}

[1] Yule, G., "Pragmatics, ” Oxford: Oxford University Press, 1996.

[2] Levinson, S. C., "Pragmatics," Cambridge: Cambridge University Press, 1983.

[3] Bekalu, M. A., "Presuppositions in News Discourse," Discourse \& Society, 17, 2006, pp 147-172.

[4] Bonyadi, A. and Samuel, M., "Linguistic Nature of Presupposition in American and Persian Newspaper Editorials. An International Journal of Linguistics," Vol 3, 2011, pp 1-16. (http://macrothink.org/journal/index.php/ijl/article/viewFile/554/pdf, retrieved in December $20^{\text {th }}, 2016$ ).

[5] Mey, L., "Pragmatics,” Oxford: Blackwell Publishers, 1993.
[6] Geurts, B. ,"Presuppositions and Pronouns," Oxford: Elsevier. Current Research in the Semantics/ Pragmatics Interface, vol. 3, 1999, pp. 1-17.

[7] Zare, J., Abbaspour, E., and Nia, Mahji R., "Presupposition Trigger A Comparative Analysis of Broadcast News Discourse," An International Journal of Linguistics, Vol 4, No. 3, 2012, pp $734-743$. (http://www.macrothink.org/jøarnal/index.php/ijl/article/viewFile/2002 /pdf, Retrieved on October 29 , 2016).

[8] Patton, M Q. and Cochran, M., "A Guide to Using Qualitative Research Methodology," 2002, pp 1-29.

(http://fieldresearch.msf.org/msf/bitstream/10144/84230/1/Qullitative \%20res earch\%20methodology.pdf, Retrieved on October 29 , 2016)

[9] Hofler, S. "Between Conciseness and Transparency: Presupposition in Legislative Texts," International Journal for the Semiotics of Law, 2013, pp 1-17.

(http://www.cl.uzh.ch/people/team/hoefler/hoefler_sela_2013.pdf, Retrieved on October 29, 2016).

[10] Miles M. B., and Huberman, A. M. \& Saldana, "Qualitative Data Analysis: a Methods Sourcebook," Edition 3, USA: SAGE Publication, 2014. 